\title{
Erken puberte ayırıcı tanısında kullanılan gonadotropin salgılatıcı hormon uyarı test sonuçlarının değerlendirilmesi
}

\section{Evaluation of gonadotropin-releasing hormone stimulation test results used in the differential diagnosis of precocious puberty}

\author{
Semih BOLU1@(D), Abdulvahit AŞIK ${ }^{2}$ (D) \\ ${ }^{1}$ Adıyaman Eğitim ve Araştırma Hastanesi, Çocuk Endokrinoloji Bölümü, 02040, Adıyaman-Türkiye \\ ${ }^{2}$ Adıyaman Eğitim ve Araştırma Hastanesi, Çocuk Sağlığı ve Hastalıkları Kliniği, 02040, Adıyaman-Türkiye
}

Atıf gösterme/Cite this article as: Bolu S, Aşık A. Erken puberte ayırıcı tanısında kullanılan gonadotropin salgılatıcı hormon uyarı test sonuçlarının değerlendirilmesi. ADYÜ Sağllk Bilimleri Derg. 2021;7(1):26-31. doi:10.30569.adiyamansaglik.862593

Öz

Amaç: Bu çalışmada 8 yaşından önce meme gelişimi ile çocuk endokrin polikliniğine başvuran k1z çocuklarına uygulanan gonadotropin salgılatıcı hormon (GnRH) uyarı test sonuçlarının değerlendirilmesi amaçlanmıştır.

Gereç ve Yöntem: Hasta verileri dosya kayıtlarının geriye yönelik incelenmesi sonucu elde edilen bu çalışmada meme gelişimi nedeniyle GnRH uyarı testi yapılmış $49 \mathrm{k} 1 \mathrm{z}$ olgu (19 gerçek erken puberte, 30 prematür telarş) alındı. Olguların tanı yaşı, antropometrik ölçümleri, kemik yaşı $(\mathrm{KY})$, bazal ve uyarılmış gonadotropin düzeyleri kaydedildi.

Bulgular: İki grubu ayırt etmek için zirve luteinizan hormon (LH) sınır değeri 4,58 IU/L alındığında duyarlılık \%84 ve özgüllük \%90, zirve LH/folikül stimüle edici hormon (FSH) sınır değeri $>0,27$ alındığında duyarlılık \%74 ve özgüllük \%80, KYtakvim yaşı farkı 1,13 alındığında duyarlılık \%63 ve özgüllük \%80 saptand1.

Sonuç: Erken meme gelişimi ile başvuran k1z çocuklarında zirve $\mathrm{LH} \geq 4,58 \mathrm{IU} / \mathrm{L}$ ve zirve $\mathrm{LH} / \mathrm{FSH}$ $\geq 0,27$ sınır değerleri gerçek erken puberteyi prematür telarştan ayırt edebilir.

Anahtar Kelimeler: Gerçek erken puberte; GnRH uyarı testi; Prematür telarş; Zirve LH/FSH; Zirve LH.

\begin{abstract}
Aim: The purpose of this study was to evaluate the results of gonadotropin-releasing hormone (GnRH) stimulation tests administered to girls presenting with breast development before the age of eight.

Materials and Methods: Forty-nine cases (19 true precocious puberty and 30 premature thelarche) administered GnRH tests due to breast development were included in the study. Patient data were obtained through a retrospective examination of file records. Cases' age at diagnosis, bone age (BA), and basal and gonadotropin levels hormone levels were recorded.

Results: A peak luteinizing hormone (LH) threshold of $4.58 \mathrm{IU} / \mathrm{L}$ was $84 \%$ sensitive and $90 \%$ specific in differentiating of two groups, while a peak LH/ follicle-stimulating hormone (FSH) threshold $>0.27$ exhibited $74 \%$ sensitivity and $80 \%$ specificity, and a BA- calendar age difference of 1.13 exhibited $63 \%$ sensitivity and $80 \%$ specificity.

Conclusion: Peak $\mathrm{LH} \geq 4.58 \mathrm{IU} / \mathrm{L}$ and peak LH/FSH $\geq 0.27$ threshold values can differentiate true precocious puberty and premature thelarche in girls presenting with early breast development.

Keywords: GnRH stimulation test; Peak LH/FSH; Peak LH; Premature thelarche; True precocious puberty.
\end{abstract}

Yazışma Adresi/Address for Correspondence: Semih BOLU, Adıyaman Eğitim ve Araştırma Hastanesi, Çocuk Endokrinoloji Bölümü, 02040, Adıyaman-Türkiye, E-mail: drsmhbl@ @otmail.com

Geliş Tarihi/Received:16.01.2021 Kabul Tarihi/Accepted:01.04.2021 Yayım Tarihi/Published online:23.04.2021 


\section{Giriş}

Hipotaloma-hipofizer gonadal eksenin etkin duruma gelmesi ile başlayan, ikincil cinsiyet karakterlerinin geliştiği, cinsel olgunlaşma ve üreme yeteneğinin kazanıldığ dönem puberte olarak bilinmektedir. ${ }^{1}$ Kızlarda sekiz, erkeklerde dokuz yaşından önce ikincil cinsiyet özelliklerinin gelişimi gerçek erken puberte olarak tanımlanmaktadır. ${ }^{2}$ Gerçek erken puberte (GEP) yaklaşı 1:5000-10000 sıklıkta görülmektedir. ${ }^{3}$ Kizlarda, erkeklere göre daha sıktır (3/1- 23/1). ${ }^{4}$ Prematür telarş (PT) tipik olarak 2 yaşından önce başlayan izole meme gelişimi ile karakterizedir. ${ }^{5} \mathrm{Bu}$ olgularda büyüme hızı normaldir. Kemik yaşı (KY) takvim yaşına (TY) göre ileri değildir. Olguların \%60'1nda klinik bulgularda gerileme gözlenirken, \%14-19'ü GEP'ye ilerleme gösterebilir. ${ }^{6,7}$ Gerçek erken puberteyi PT'tan ayırt etmek için büyüme hızı, KY ölçümü, pelvik ultrason bulguları, bazal ve uyarılmış gonadotropin seviyeleri birlikte değerlendirilmelidir. GEP'yi PT'tan ayırt etmede kullanılan gonadotropin salg1latic1 hormon (GnRH) uyar1 testi altın standart bir yöntem olarak bilinmektedir. ${ }^{8}$ Çeşitli çalışmalar ile bazal ve uyarılmış luteinizan hormon (LH) düzeyleri değerlendirilmiş ve bu çalışmalarda yüksek duyarlılık ve özgüllükte eşik değerleri bildirilmiştir. ${ }^{9-11}$

$\mathrm{Bu}$ çalışma sekiz yaşından önce meme gelişimi ile başvuran kız çocuklarında GEP ve PT ayırımında kullanılan GnRH uyarı test sonuçlarının karşılaştırılması amacı ile yapılmıştır.

\section{Gereç ve Yöntem}

\section{Araştırmanın tipi}

$\mathrm{Bu}$ çalışmada hasta dosyaları retrospektif olarak değerlendirilmiştir.

\section{Araştırmanın evreni ve örneklemi}

Çalışmanın evreni 2016-2020 yılları arasında Adıyaman Eğitim ve Araştırma Hastanesi Çocuk Endokrin Polikliniği'ne meme gelişimi ile başvuran, klinik muayene ve bazal hormonal değerlendirme sonrasında GEP ve PT tanıları tam olarak ayrılamayan ve bu nedenle GnRH uyarı testi yapılan 8 yaş altındaki kız olgulardan oluşturuldu.

\section{Veri toplama araçları}

Çalışmanın verileri hastaların başvuru yaşı, şikayetlerin başlama yaşı, puberte evresi, boy $(\mathrm{cm})$, vücut ağırlığı $(\mathrm{kg})$ ve vücut kitle indeksini (VKI) içeren antropometrik ölçümleri, bazal ve uyarılmış gonadotropin ölçümleri, uterus uzun çapı ve ortalama over çapını içeren pelvik ultrason bulgularından oluşmaktadır.

Hastanemizde gonadotropin salgilatic1 hormon uyarı testi luteinize edici hormonu salgılatıc1 hormonun (LHRH) intravenöz olarak $100 \mathrm{mcg} / \mathrm{m}^{2}$ dozunda verilmesi sonras1 20. ve 60. dakikalarda folikül stimüle edici hormon (FSH), LH ve estradiol ölçülmesi ile yapılmaktadır. FSH ve LH ölçümünde immünokemilüminesans (İCMA) yöntemi, KY değerlendirmesinde Greulich ve Pyle atlası kullanıldığı, puberte evrelemesi Marshall ve Tanner kriterlerine göre yapıldı ğ bilgisi dosya kayıtlarından elde edildi. ${ }^{12,13}$ Hastaların boy ve kilo ölçümleri dijital tartı ve duvara monte olan Harpender stadyometre kullanılarak ölçüldüğü saptandı. Vücut kitle indeksi (VKİ) kilogram cinsinden a ăırlığın metre cinsinden yüksekliğin karesine $\left(\mathrm{kg} / \mathrm{m}^{2}\right)$ bölünmesiyle hesaplandı.

Sekiz yaşından önce meme gelişimi başlaması yanı sıra KY/TY >1 ve GnRH testi yapıldığında zirve LH'ın $>5$ IU/L olması GEP olarak tanımlandı. ${ }^{14}$ Tek başına meme gelişimi olan, $\mathrm{KY}=\mathrm{TY}$ veya $\mathrm{KY}<\mathrm{TY}$ olan ve en az bir y1llik takip sonucunda pubertede ilerleme olmayan olgular PT olarak kabul edildi.

Verileri eksik olan, periferik erken puberteye sahip ve eşlik eden hormonal bozuklukları olan olgular ile santral sinir sistemi görüntülemesinde organik bozukluk saptanan olgular çalışma dışı bırakıldı.

\section{Verilerin analizi}

İstatistiksel analiz için SPPS 25 (IBM Corp. Released 2017. IBM SPSS Statistics for Windows, Version 25.0. Armonk, NY: IBM Corp.) programı kullanıldı. Tanımlayıc1 istatistik olarak ortalama, standart sapma ve yüzdeler hesaplandı. Anlamlılık düzeyi olarak 
$p<0,05$ kabul edildi. Sayısal değişkenlerin normallikleri Kolmogorov-Smirnov testi ile kontrol edildi. Grup karşılaştırmasında MannWhitney $U$ ve Student $t$ testi, grup oranlarının karşılaştırmasında ki-kare testi uygulandı. Gerçek erken puberte ve prematüre telarş tanılı olguları ayırt etmede kullanılacak değişkenleri belirlemek için univariate lojistik regresyon analizleri yapıldı.

Tek değişkenli regresyon analizinde anlamlı gelen etmenler ROC analizi ile saptanan eşik değerlere göre gruplandırıldı. Univariate lojistik regresyon analizi sonucunda GEP ve PT tanılı olguları ayırt etmede kullanılacak değişkenleri bir arada değerlendirmek için multivariate lojistik regresyon analizi yapıldı.

\section{Araştırmanın etik boyutu}

$\mathrm{Bu}$ çalışma için ilgili Üniversitenin Tıp Fakültesi Girişimsel Olmayan Etik
Kurulu'ndan 2020/5-16 karar sayısı ile etik kurul izni alınmıştır.

\section{Bulgular}

$\mathrm{Bu}$ çalışmaya yaşları 1,8 ile 7,9 yıl (ortalama 6,5 $\pm 1,3$ ) arasında değişen, 19'u $(\% 38,8)$ erken puberte ve 30'u $(\% 61,2)$ prematür telarş tanısı alan toplam $49 \mathrm{k} 1 \mathrm{z}$ olgu alındı. Gerçek erken puberte ve prematür telarş gruplarında yakınmaların başlama yaşları ve tanı alma yaşları benzerdi. GEP'li grubun tanıda KY-TY farkı PT'lı gruba göre anlamlı derecede yüksek iken kemik yaşına göre düzeltilmiş boy-standart sapma skoru (SSS) PT'lı gruba göre daha düşük bulundu. GEP ve PT'li gruplar arasinda bazal LH ve FSH düzeyleri açısından anlamlı bir fark saptanmazken, GEP'li grubun zirve LH ve zirve LH/FSH oranı PT'lı gruba göre anlamlı düzeyde yüksek bulundu (Tablo 1).

Tablo 1. Santral erken puberte ve prematür telarş tanılı olguların klinik, antropometrik ve laboratuvar bulgularına ilişkin sonuçların karşılaştırılması.

\begin{tabular}{|c|c|c|c|}
\hline & Gerçek Erken Puberte $(n=19)$ & Prematür Telarş $(n=30)$ & $p$ \\
\hline Takvim yaşı (y1l) & $6,73 \pm 1,10$ & $6,45 \pm 1,53$ &, $501^{\mathrm{a}}$ \\
\hline Kemik yaş1 (yıl) & $8,00 \pm 1,53$ & $7,17 \pm 1,73$ &, $093^{\mathrm{a}}$ \\
\hline Semptom başlama yaşı (yıl) & $6,20 \pm 1,27$ & $5,56 \pm 2,07$ & $232^{\mathrm{a}}$ \\
\hline KY-TY (y1l) & $1,27 \pm 0,82$ & $0,71 \pm 0,55$ &, $006^{\mathrm{a}}$ \\
\hline VKİ-SSS & $0,22 \pm 1,11$ & $0,30 \pm 0,82$ &, $781^{\mathrm{a}}$ \\
\hline Boy-SSS & $0,45 \pm 1,12$ & $0,44 \pm, 76$ & $961^{\mathrm{a}}$ \\
\hline TEB-SSS & $-0,35 \pm 0,84$ & $0,29 \pm 1,30$ &, $044^{\mathrm{b}}$ \\
\hline Ergenlik Evresi & & & $.489^{\mathrm{c}}$ \\
\hline Tanner 2 & $15(\% 78.9)$ & $21(\% 70)$ & \\
\hline Tanner 3 & $4(\% 21.1)$ & $9(\% 20)$ & \\
\hline Ortalama over hacmi & $1,84 \pm 1,29$ & $1,72 \pm 1,36$ &, $774^{\mathrm{a}}$ \\
\hline Uterus çap1 & $32,42 \pm 6,33$ & $31,37 \pm 7,10$ &, $608^{\mathrm{a}}$ \\
\hline Bazal FSH & $2,80 \pm 1,74$ & $2,65 \pm 1,50$ &, $742^{\mathrm{a}}$ \\
\hline Bazal LH & $0,27 \pm 0,25$ & $0,21 \pm 0,20$ &, $351^{\mathrm{b}}$ \\
\hline Bazal LH/FSH & $0,11 \pm 0,07$ & $0,09 \pm 0,10$ &, $674^{\mathrm{b}}$ \\
\hline Zirve FSH & $16,59 \pm 6,44$ & $16,25 \pm 6,61$ &, $859^{\mathrm{a}}$ \\
\hline Zirve LH & $9,48 \pm 8,19$ & $3,02 \pm 1,28$ &, $003^{\mathrm{a}}$ \\
\hline Zirve LH/FSH & $0,66 \pm 0,62$ & $0,20 \pm 0,09$ & $.005^{\mathrm{a}}$ \\
\hline
\end{tabular}

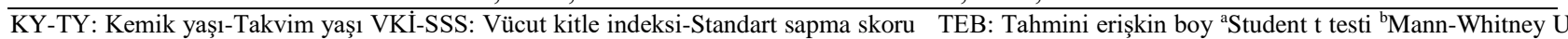
testi ${ }^{\mathrm{c}} \mathrm{ki}-\mathrm{kare}$ testi

Gerçek erken puberte ve prematür telarş tanılı olguları ayırt etmede kullanılacak değişkenler için univariate lojistik regresyon analizleri yürütüldü. Elde edilen sonuçlar KYTY fark1, zirve LH değeri ve zirve LH/FSH oranının iki grup arasındaki farklılaşmaları ayırt etmede kullanılabileceğini göstermiştir (Tablo 2). Bu çalışmada KY-TY farkı, zirve LH değeri ve zirve LH/FSH oranının duyarlılık ve özgüllük değerleri ve bu değerlere ilişkin uygun kesme noktaları da incelendi (Tablo 3). İki grubu ayırt etmek için zirve LH sınır değeri 4,58 IU/L alındığında duyarlılık \%84 ve özgüllük \%90, zirve LH/FSH sınır değeri $>0,27$ alındığında duyarlılık \%74 ve özgüllük $\% 80$ ve KY-TY farkı 1,13 alındığında duyarlılık \%63 ve özgüllük \%80 olarak saptandı. Univariate lojistik regresyon analizi sonucunda erken puberte ve prematür telarş tanılı olguları ayırt 
etmede kullanılacak değişkenleri bir arada değerlendirmek için multivariate lojistik regresyon analizi yapıldı. Ancak bir önceki basamakta anlamlı bulunan zirve LH ve zirve LH/FSH arasında yüksek düzeyde korelasyon olması sebebiyle iki ayrı multivariate lojistik regresyon analizi uygulandi. Elde edilen sonuçlar zirve LH, zirve LH/FSH oranı ve KY-TY farkının iki grubu ayırmada anlamlı katkısının olduğunu göstermiştir (Tablo 4 ve Tablo 5).

Tablo 2. Puberte prekoks ve prematür telarş tanılı olguları ayırt etmede kullanılabilecek değişkenler için univariate lojistik regresyon analizi sonuçları.

\begin{tabular}{|c|c|c|c|c|}
\hline & \multirow{2}{*}{ Odds oranı } & \multicolumn{2}{|c|}{ \%95 Güven Aralığ1 } & \multirow{2}{*}{$p^{*}$} \\
\hline & & Alt sinır & Üst sinır & \\
\hline KY-TY & 0,292 & 0,112 & 0,761 & 0,012 \\
\hline VKİ-SSS & 1,095 & 0,586 & 2,048 & 0,155 \\
\hline Kemik yaşına göre boy-SSS & 1,73 & 0,946 & 3,167 & 0,075 \\
\hline Ergenlik Evresi & 0,662 & 0,161 & 2,403 & 0,491 \\
\hline Ortalama over hacmi $(\mathrm{mL})$ & 0,933 & 0,586 & 2,483 & 0,768 \\
\hline Uterus uzun çap1(mm) & 0,977 & 0,894 & 1,067 & 0,600 \\
\hline Bazal FSH & 0,940 & 0,654 & 1,351 & 0,736 \\
\hline Bazal LH & 0,285 & 0,021 & 3,908 & 0,347 \\
\hline Bazal LH/FSH & 0,243 & 0,000 & 154,588 & 0,667 \\
\hline Zirve FSH & 0,992 & 0,907 & 1,085 & 0,855 \\
\hline Zirve LH & 0,340 & 0,180 & 0,642 & 0,001 \\
\hline Zirve LH/FSH & 0,000 & 0,000 & 0,026 & 0,003 \\
\hline
\end{tabular}

KY-TY: Kemik yaşı-Takvim yaşı VKİ-SSS: Vücut kitle indeksi-Standart sapma skoru *Univariate Lojistik Regresyon Analizi

Tablo 3. Değişkenlere ilişkin özgüllük ve duyarlık değerleri.

\begin{tabular}{lccccc}
\hline Değişkenler & Duyarlılık & Özgüllük & Eşik değer & AUC & $p^{*}$ \\
\hline KY-TY & 63 & 80 & 1,13 & 0,715 & 0,012 \\
Zirve LH & 84 & 90 & 4,58 & 0,903 & 0,000 \\
Zirve LH/FSH & 74 & 80 & 0,27 & 0,861 & 0,000
\end{tabular}

KY-TY: Kemik yaşı-Takvim yaşı *ROC Analizi

Tablo 4. Puberte prekoks ve prematür telarş tanılı vakaları ayırt etmede kullanılabilecek değişkenler için multivariate lojistik regresyon analizi sonuçları (Birincil model).

\begin{tabular}{lcccc}
\hline \multirow{2}{*}{ Değişkenler } & \multirow{2}{*}{ Odds oranı } & \multicolumn{2}{c}{$\% 95$ Güven Aralı̆̆ } & \multirow{2}{*}{$p^{*}$} \\
\cline { 3 - 4 } & & Alt sinır & Üst sınır & 0,002 \\
\hline KY-TY & 0,105 & 0,019 & 0,584 & 0,010 \\
\hline Zirve LH & 0,206 & 0,076 & 0,559 & 0,016 \\
\hline
\end{tabular}

KY-TY: Kemik yaşı-Takvim yaşı *Multivariate Lojistik Regresyon Analizi

Tablo 5. Puberte prekoks ve prematür telarş tanılı olguları ayırt etmede kullanılabilecek değişkenler için multivariate lojistik regresyon analizi sonuçları (İkincil model)

\begin{tabular}{lcccc}
\hline \multirow{2}{*}{ Değişkenler } & \multirow{2}{*}{ Odds oranı } & \multicolumn{2}{c}{$\% 95$ Güven Aralığ } & \multirow{2}{*}{$p^{*}$} \\
\cline { 3 - 4 } & & Alt sınır & Üst sınır & 0,032 \\
\hline KY-TY & 0,198 & 0,045 & 0,871 & 0,001 \\
\hline Zirve LH/FSH & 0,000 & 0,000 & 0,022 & 0,000 \\
\hline
\end{tabular}

KY-TY: Kemik yaşı-Takvim yaşı *Multivariate Lojistik Regresyon Analizi

\section{Tartışma}

Gerçek erken puberteye sahip olgularda hızlı kemik olgunlaşması nedeniyle epifiz hatlarının erken kapanması erişkin dönemde boy kısalığına yol açabilir. Bu olgulara erken dönemde tanı konulup tedavi başlanması erişkin dönem boy kaybını önleyebilir. ${ }^{4} \mathrm{Bu}$ nedenle GEP'nin izole meme gelişimi ile giden PT'tan ayırt edilmesi önemlidir. Gerçek erken puberteyi PT'tan ayırt etmek için ileri kemik yaşı ve artmış büyüme hızı gibi klinik bulgular yanında görüntüleme yöntemleri, bazal ve uyarılmış gonadotropin ölçümleri kullanılmaktadır. ${ }^{15}$ GEP'li olgularda uterus uzun çapı ve over volümlerinin artmış olduğu bildirilmiştir. ${ }^{16}$ Çalışmamızda hem uterus uzun çapı hem de over volümü GEP'li olgularda PT'lı olgulardan daha fazla olsa da, istatistiksel olarak anlamlı değildi. Literatürden farklı olan bu durum ultrasonografi ölçümlerinin farklı hekimler tarafından yapılmış olmasına bağlı olabilir. Ergenlik başlangıcında LH salınımı nokturnal 
ve pulsatil olduğundan GEP'de ergenlik evresi ile ilişkili olarak bazal LH seviyeleri bilgi verici olmayabilir. Bununla birlikte ICMA ve IFMA gibi üçüncü kuşak ölçüm yöntemlerinin kullanılması erken puberte tanısında bazal değerlerin tanısal değerini artırmıştır. Vurallı ve ark. $\geq 0,65$ IU/L bazal LH düzeyinin GEP'yi göstermede bir tarama testi olarak kullanılabileceğini bildirmişlerdir. ${ }^{17}$ Benzer şekilde Kandemir ve ark. bazal LH düzeyinin $>0,3$, Neely ve ark. ise $>0,1^{\prime}$ 'in olmasinin erken puberteyi göstermede yüksek duyarlılık ve özgüllüğe sahip olduğunu göstermişlerdir., ${ }^{8,18}$ Bununla birlikte Lee ve ark. erken ergenlik şüphesi ile başvuran ve bazal $\mathrm{LH}$ düzeyleri $<0,1 \mathrm{U} / \mathrm{L}$ saptanan olgulara GnRH uyarı testi yaptıklarında bu olguların önemli bir kısmında $(\% 55,6)$ pubertal yanıt elde etmişlerdir. ${ }^{11}$ Yapılan çalışmalar bazal ve zirve FSH düzeylerinin GEP'de zayıf bir tanısal değere sahip olduğunu ve uygulamada güvenilir bir değişken olarak kullanılamayacağını göstermiştir. ${ }^{19,20}$ Çalışmamızda GEP ve PT olguları arasında bazal $\mathrm{LH}$, bazal FSH ve zirve $\mathrm{FSH}$ düzeyleri bakımından anlamlı fark bulunmamış ve elde ettiğimiz sonuçlar bu parametrelerin GEP'yi PT'tan ayırt etmede duyarlı bir değişken olarak kullanılamayacağını düşündürmüştür.

Gonadotropin salgilatic1 hormon uyar1 testi, erken ergenliğin klinik belirtileri olan olgularda hipotalamus-hipofiz-gonadal eksenin etkin duruma geldiğini göstermede kullanılan altın standart bir yöntemdir. GnRH'a zirve LH yanıtlarının ölçüm yöntemlerine göre değişiklik gösterdiği ve farklı çalışmalarda 3,3 IU/L ve 5 IU/L'nin üzerindeki değerlerin erken ergenliği göstermede yüksek duyarlılık ve özgüllüğe sahip olduğu bildirilmiştir. ${ }^{14}$ Çalışmamızda erken meme gelişimi ile gelen kız olgularda GnRH'a LH yanıtları değerlendirildiğinde, zirve LH değerinin GEP'yi PT'tan ayırt ettiren önemli bir parametre olduğu ve GEP için zirve LH sınır değeri 4,58 IU/L alındığında duyarlılığın \%84 ve özgüllügün $\% 90$ olduğu bulunmuştur.

Yapılan çalışmalar zirve LH/FSH oranının GEP tanısında değerli bir gösterge olabileceğini göstermiş̧tir. Mogensen ve ark. zirve LH/FSH değerinin 0,66'nın üzerinde olmasinı pubertal yanıt olarak kabul etmişlerdir. $^{21}$ Çatlı ve ark. GEP tanısında zirve LH/FSH oranının en iyi duyarlık ve özgüllüğe sahip değişken olduğunu, zirve LH/FSH oranı $>0,24$ alındığında GEP için duyarlılığın $\% 100$ ve özgüllüğün $\% 84$ olduğunu bildirmişlerdir. ${ }^{20}$ Literatürle uyumlu olarak, çalışmamızda zirve LH/FSH oranının GEP'li olguları PT'tan ayırmada önemli bir değişken olduğu saptanmıştır. Bu çalışmada zirve LH/FSH sinır değeri $>0,27$ alındığında duyarlılığın $\% 74$ ve özgüllüğün $\% 80$ olduğu bulunmuştur.

\section{Sonuç}

Sonuç olarak çalışmamızda GEP ve PT ayırımında zirve LH ve zirve LH/FSH oranının önemli bir değişken olduğu ve GEP için zirve LH sınır değeri 4,58 IU/L alındığında duyarlılığın \%84 ve özgüllüğün $\% 90$, zirve LH/FSH sinır değeri $>0,27$ alındığında duyarlılığın \%74 ve özgüllüğün $\% 80$ olduğu bulunmuştur. Bununla birlikte GEP ve PT ayırımında laboratuvar veriler tek başına kullanılmamalı, klinik bulgularla birlikte değerlendirilmelidir.

\section{Araştırmanın Etik Boyutu}

Araştırmanın yapılabilmesi için ilgili Üniversitenin Girişimsel Olmayan Klinik Araştırmalar Etik Kurulu'ndan etik kurul onayı alınmıştır (2020/5-16).

\section{Bilgilendirilmiş Onam}

Çalışma retrospektif olarak yapıldığından verilerin toplandığ 1 hastaneden yazılı izin alınmıştır.

\section{Yazar Katkıları}

Çalışma konsepti/Tasarımı: SB, AA; Veri toplama: SB; Veri analizi ve yorumlama: AA, SB; Literatür taraması: SB, AA; Yazan: SB

\section{Teşekkürler}

Araştırmada verileri kullanılarak bilimsel katkı sağlayan hasta ve hasta yakınlarına teşekkür ederiz.

\section{Çıkar Çatışması Beyanı}

Yazarlar arasında çıkar çatışması bulunmamaktadir. 


\section{Araştırma Desteği}

$\mathrm{Bu}$ çalışmada herhangi bir fon veya destekten yararlanılmamıştır.

\section{Beyanlar}

Çalışmamız 18-20 Aralık 2020 tarihinde çevrimiçi yapılan Sağlıklı Büyüyen Çocuk Kongresi'nde sözel bildiri olarak sunulmuştur.

\section{Hakem Değerlendirmesi}

Diş bağımsız.

\section{Kaynaklar}

1. Brito VN, Spinola-Castro AM, Kochi C, Kopacek C, Silva PC, Guerra-Júnior G. Central precocious puberty: revisiting the diagnosis and therapeutic management. Arch Endocrinol Metab. 2016;60(2):163-72.

2. Parent AS, Teilmann G, Juul A, Skakkebaek NE, Toppari J, Bourguignon JP. The timing of normal puberty and the age limits of sexual precocity: variations around the world, secular trends, and changes after migration. Endocr Rev 2003; 24(5):668-93.

3. Partsch CJ, Sippell WG. Treatment of central precocious puberty. Best Pract Res Clin Endocrinol Metab. 2002;16(1):165-89.

4. Antoniazzi F, Zamboni G. Central precocious puberty: current treatment options. Paediatr Drugs. 2004;6(4):211-31.

5. Chiabotto P, Costante L, de Sanctis C. Premature thelarche and environmental pollutants. Minerva Med. 2006;97(3):277-85.

6. Volta $\mathrm{C}$, Bernasconi $\mathrm{S}$, Cisternino $\mathrm{M}$, et al. Isolated premature thelarche and thelarche variant: clinical and auxological followup of 119 girls. J Endocrinol Invest. 1998;21(3):180-83.

7. Lee CT, Tung YC, Tsai WY. Premature thelarche in Taiwanese girls. J Pediatr Endocrinol Metab. 2010;23(9):879-84.

8. Neely EK, Wilson DM, Lee PA, Stene M, Hintz RL. Spontaneous serum gonadotropin concentrations in the evaluation of precocious puberty. J Pediatr. 1995;127(1):47-52.

9. Lee HS, Park HK, Ko JH, Kim YJ, Hwang JS. Utility of Basal luteinizing hormone levels for detecting central precocious puberty in girls. Horm Metab Res. 2012;44(11):851-54

10. Pasternak Y, Friger M, Loewenthal N, Haim A, Hershkovitz E. The utility of basal serum LH in prediction of central precocious puberty in girls. Eur $J$ Endocrinol. 2012;166(2):295-99.

11. Lee DS, Ryoo NY, Lee SH, Kim S, Kim JH. Basal luteinizing hormone and follicular stimulating hormone: is it sufficient for the diagnosis of precocious puberty in girls? Ann Pediatr Endocrinol Metab. 2013;18(4):196-201.

12. Greulich WW, Pyle SI. Radiographic Atlas of Skeletal Development of the Hand and Wrist. 2nd ed. California:Stanford University Press; 1959

13. Marshall WA, Tanner JM. Variations in pattern of pubertal changes in girls. Arch Dis Child. 1969;44(235):291-303.

14. Carel JC, Eugster EA, Rogol A, et al. Consensus statement on the use of gonadotropin-releasing hormone analogs in children. Pediatrics. 2009;123(4):e752-e762.

15. Della Manna T, Setian N, Damiani D, Kuperman H, Dichtchekenian V. Premature thelarche: identification of clinical and laboratory data for the diagnosis of precocious puberty. Rev Hosp Clin Fac Med Sao Paulo. 2002;57(2):49-54.

16. Battaglia C, Mancini F, Regnani G, Persico N, Iughetti L, De Aloysio D. Pelvic ultrasound and color Doppler findings in different isosexual precocities. Ultrasound Obstet Gynecol 2003;22(3):277-83.

17. Vurallı D, Gönç EN, Özön ZA, Alikaşifoğlu A. Adequacy of basal luteinizing hormone levels in the diagnosis of central precocious puberty. Turk Pediatri Ars. 2020;55(2):131-38.

18. Kandemir N, Demirbilek H, Özön ZA, Gönç N, Alikaşifoğlu A. $\mathrm{GnRH}$ stimulation test in precocious puberty: single sample is adequate for diagnosis and dose adjustment. J Clin Res Pediatr Endocrinol. 2011;3(1):12-7.

19. Yazdani P, Lin Y, Raman V, Haymond M. A single sample GnRHa stimulation test in the diagnosis of precocious puberty. Int J Pediatr Endocrinol. 2012;2012(1):23.

20. Çatlı G, Erdem P, Anık A, Abacı A, Böber E. Clinical and laboratory findings in the differential diagnosis of central precocious puberty and premature thelarche. Turk Pediatri Ars. 2015;50(1):20-6.

21. Mogensen SS, Aksglaede L, Mouritsen A, et al. Diagnostic work-up of 449 consecutive girls who were referred to be evaluated for precocious puberty. J Clin Endocrinol Metab. 2011;96(5):1393-401. 